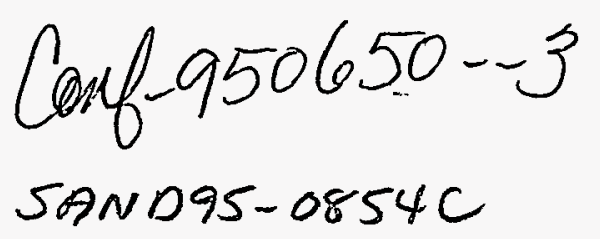

\title{
SELF-CONSISTENT TEMPERATURE COMPENSATION FOR RESONANT SENSORS WITH APPLICATION TO QUARTZ BULK ACOUSTIC WAVE CHEMICAL SENSORS
}

\author{
James H. Smith* and Stephen D. Senturia** \\ *Sandia National Laboratories, MS-1080, Albuquerque, NM 87185-1080, USA \\ **Massachusetts Institute of Technology, Room 39-567, 77 Mass. Ave., Cambridge, MA, 02139, USA
}

\section{SUMMARY}

Since resonant sensors have a temperature sensitivity which is often greater than their sensitivity to the phenomena they are being used to detect, it is imperative to include either temperature control or temperature compensation in any resonant sensor system. We have developed a temperature-compensation scheme for resonant sensors which is amenable to integration into a resonator-driver integrated circuit. An integrated circuit incorporating this scheme has been designed, built, and tested.

\section{INTRODUCTION}

Resonant sensors have numerous applications as both physical sensors and chemical sensors. Since these resonators have a sensitivity to temperature which is often greater than their sensitivity to the extremely small mass changes they are being used to detect, it is imperative to either control their temperature or compensate for temperature changes. We have developed a temperature compensation circuit which is amenable to integration onto a resonator-driver integrated circuit.

A number of methods for temperature compensation utilizing two resonators have been described in the literature [1, 2]. A method utilizing a composite piezoelectric film to provide a near-zero temperature drift has also been described [3]. A method similar to the compensation scheme used here has been previously described for use with external frequency counters, although no temperature-stability data was reported [4].

\section{TEMPERATURE COMPENSATION}

The temperature compensation scheme uses the conventional sensing setup of two resonators, a sense resonator (with frequency $f_{1}$ ) and a reference resonator (with frequency $f_{2}$ ). The first-order variation in frequency $(f)$ of each resonator with respect to temperature (t) and the sensed quantity $(x)$ can be represented as

$$
f=f_{0} T(t) X(x)
$$

where $f_{0}$ is the unperturbed resonant frequency, $T(t)$ is $\sim 1$, and represents variation with temperature, and $X(x)$ is also $\sim 1$, and represents variation with the quantity sensed. In order to provide both a time base for frequency counting and to compensate that count for changes in temperature, the reference resonator is used along with a divider that reduces $f_{2}$ by the factor $D$ and forms the timebase $\left(D / f_{2}\right)$. Thus the result of the counting operation $(N)$ can be represented by the divider (D) and the ratio of $f_{1}$ to $f_{2}$. Since $f_{2}$ is invariant with respect to the sensed quantity $(x)$, this expression for $\mathrm{N}$ can be reduced to yield

$$
N=D \frac{f_{1}}{f_{2}}=D \frac{f_{01} T(t) X(x)}{f_{02} T(t) X(0)}=D \frac{f_{01}}{f_{02}} X(x) \text {. }
$$

Thus the first-order effects of temperature and other common mode interferents can be eliminated from the final signal.

\section{RESONATOR-DRIVER IC}

This temperature-compensation scheme is illustrated schematically in Figure 1 along with the addition of a multiplexor to reduce the number of data lines from the integrated circuit. An integrated circuit using this compensation scheme has been built at Sandia's Microelectronics Development Laboratory in a $2 \mu \mathrm{m}$ CMOS process. This chip incorporates resonator drivers for three bulk acoustic wave resonators, the temperaturecompensation scheme for two of the resonators using the third resonator as the reference resonator, multiplexing interface circuitry, and buffering circuitry.

\section{RESULTS}

This circuit and its temperature compensation scheme have been successfully tested with good results. Figure 2 shows variations in frequency (from an initial resonant frequency of approximately $22 \mathrm{MHz}$ ) for two resonators over a 16-hour period in a laboratory area with ordinary room temperature fluctuations due to cycling of the building air conditioning system $\left( \pm 1^{\circ} \mathrm{C}\right)$. These frequencies were recorded from two external frequency counters (incorporating their own temperature controlled timebases) along with the frequency output from the temperature-compensated on-chip counter (using frequency 2 as a timebase). The "On-Chip Counter" trace shows that the compensated output fluctuates only at the level of the least-significant bit, corresponding to \pm 0.4 $\mathrm{Hz}$. Because this fluctuation appears only in the leastsignificant bit, we do not yet know the lower limit. The goal for chemical sensor applications is $\pm 0.1 \mathrm{~Hz}$, which appears achievable with this approach. A new chip is in fabrication with a higher-resolution output counter. 


\section{DISCLAIMER}

This report was prepared as an account of work sponsored by an agency of the United States Government. Neither the United States Government nor any agency thereof, nor any of their employees, makes any warranty, express or implied, or assumes any legal liability or responsibility for the accuracy, completeness, or usefulness of any information, apparatus, product, or process disclosed, or represents that its use would not infringe privately owned rights. Reference herein to any specific commercial product, process, or service by trade name, trademark, manufacturer, or otherwise does not necessarily constitute or imply its endorsement, recommendation, or favoring by the United States Government or any agency thereof. The views and opinions of authors expressed herein do not necessarily state or reflect those of the United States Government or any agency thereof. 


\section{DISCLAIMER}

Portions of this document may be illegible in electronic image products. Images are produced from the best available original document. 
Nevertheless, the output has much better stability than can be achieved by subtracting the two frequencies.

Additional tests were performed over a controlled temperature range of $40^{\circ} \mathrm{C}$ to $60^{\circ} \mathrm{C}$. Figure 3 shows the drift with time of two resonators held at $40^{\circ} \mathrm{C}$, quickly ramped to $60^{\circ} \mathrm{C}$ (Heater On), and slowly cooled back to $40^{\circ} \mathrm{C}$ (Heater Off). The signal compensated using the onchip temperature compensation (On-Chip Counter) shows a deviation of $\sim 2 \mathrm{~Hz}$ during this temperature cycling. The signal which was compensated by subtracting the readings of two external frequency counters (External Counter Difference) shows a deviation of $\sim 25 \mathrm{~Hz}$ during this same cycle. The uncompensated frequency drifted over $100 \mathrm{~Hz}$ during this same thermal cycle.

Figure 4 shows the response of a resonant sensor with a poly-(isobutylene) coating exposed to various concentrations of trichloroethylene [5]. This sensor combined with a prototype version of the resonator driver/temperature compensation/multiplexing circuit is shown in Figure 5. The overall size of a three element sensor complete with control, temperature compensation, and interface circuitry is the size of a postage stamp and only $1 \mathrm{~mm}$ thick.

\section{CONCLUSIONS}

A self-consistent temperature-compensation scheme has been designed and fabricated as part of a resonatordriver integrated circuit. This circuit has shown approximately an order of magnitude improvement in compensation over the conventional frequency-subtraction temperature compensation method using external frequency counters. The development of this temperature compensation scheme and integrated circuit enable the reduction of a complete resonant-sensing system into a package the size of a postage stamp.

\section{ACKNOWLEDGEMENT}

The authors are grateful to the staff, technicians, and operators of Sandia's Microelectronics Development Laboratory for their fabrication of the integrated resonator-driver circuit. Jim Murray of Sandia's Custom Microcircuit Department should also be acknowledged for his contribution to the circuit design and mask layout. This work, performed at Sandia National Laboratories, was supported by the U.S. Department of Energy under contract DE-AC04-94AL85000.

\section{REFERENCES}

[1] Slobodnik, A; Colvin, R.; Roberts, G.; and Silva, J.; "A Digitally Compensated Saw Oscillator", Proc. 1981 Ultrasonics Symposium, pp. 135-138.

[2] Alder, J.; Fox, C.; Przybylko, A.; Rezgui, N.; and Snook, R.; Analyst., 114(9), p. 1163, 1989.

[3] Gunshor, R.; Martin, S.; and Pierret, F.; "Surface Acoustic Wave Devices on Silicon", Proc. 1982 Int. Conf. on Solid State Devices, pp. 37-41.

[4] Joshi, S.; "A Temperature Compensated High Voltage Probe Using Surface Acoustic Waves", Proc. 1982 Ultrasonics Symposium, pp. 317-320.

[5] Smith, J.; Ricco, A; Martin, S; and Koehler, D.; "Miniature Quartz Thickness-Shear Mode Resonator Sensor Array with Integrated Control Electronics", Late News Paper at Sensors and Actuators '94.

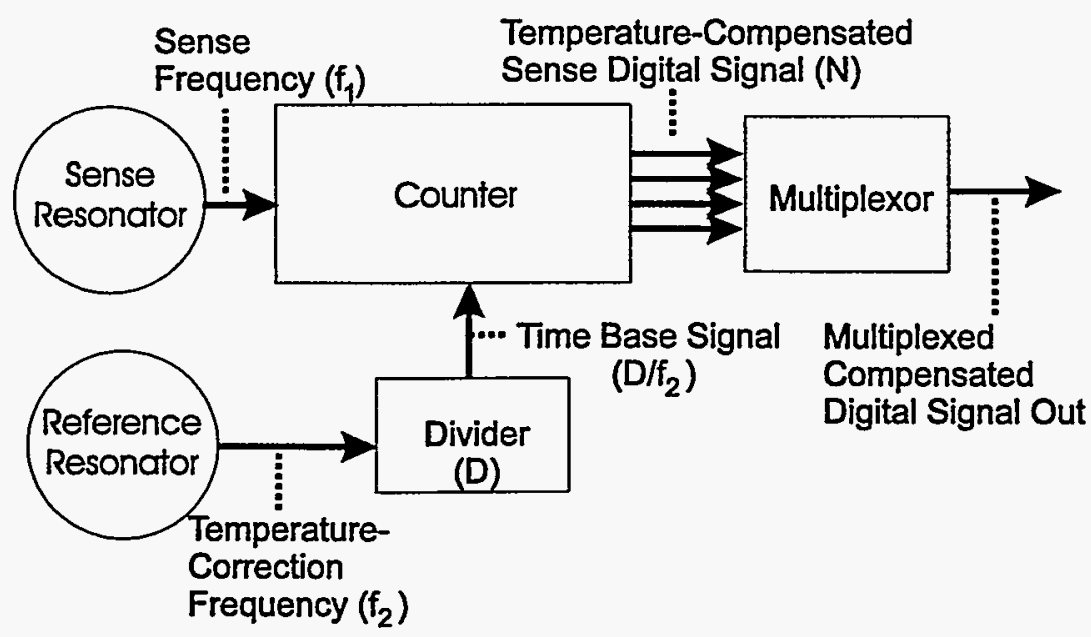

Figure 1. Schematic representation of temperature compensation scheme. A reference resonator is used to generate the timebase for a frequency counter that counts the frequency of a sense resonator. This compensation/counting circuitry has been combined with resonator drivers and interface multiplexors in a single CMOS die. 


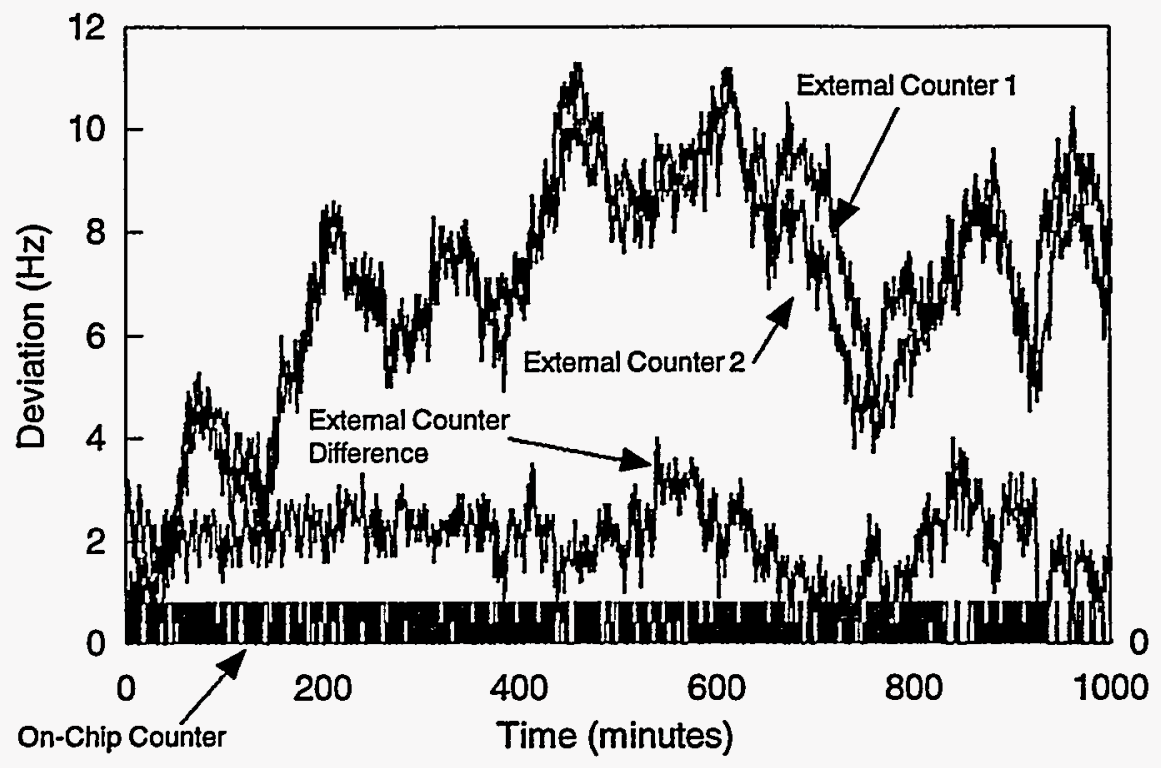

Figure 2. The "On-Chip Counter" signal shows toggling in the least significant bit of the CMOS IC temperature compensated resonator output, which corresponds to $\pm 0.4 \mathrm{~Hz}$ fluctuation. For comparison, we also show the changes in frequency of two resonators, driven by the CMOS IC, but counted by two external (Keithley model 775A) frequency counters (External 1 and External 2). These changes are of order $\pm 5 \mathrm{~Hz}$, and their difference (External Counter Difference) is much larger than fluctuations of the temperature compensated resonator. The frequency drifts in the externally counted signals are estimated to correspond to room temperature changes of order $\pm 1^{\circ} \mathrm{C}$.

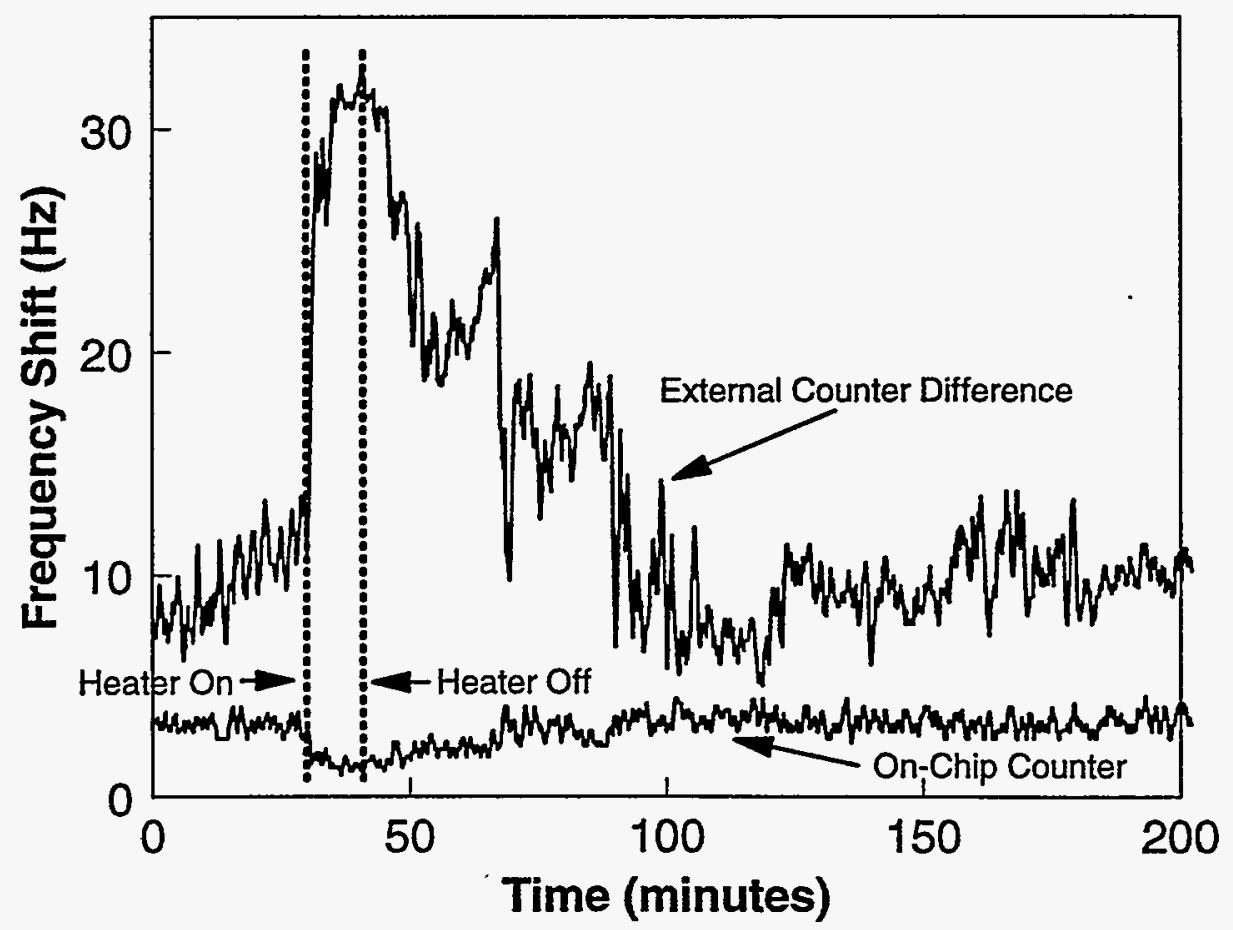

Figure 3. The "On-Chip Counter" temperature-compensated signal shows a deviation of $\sim 2 \mathrm{~Hz}$ during a temperature cycle from $40^{\circ} \mathrm{C}$ to $60^{\circ} \mathrm{C}$ and back to $40^{\circ} \mathrm{C}$. The signal compensated by subtracting the readings of two external frequency counters (External Counter Difference) shows a deviation of $\sim 25 \mathrm{~Hz}$ during this same cycle. The uncompensated (not shown) frequency drifted over $100 \mathrm{~Hz}$ during this same thermal cycle. 


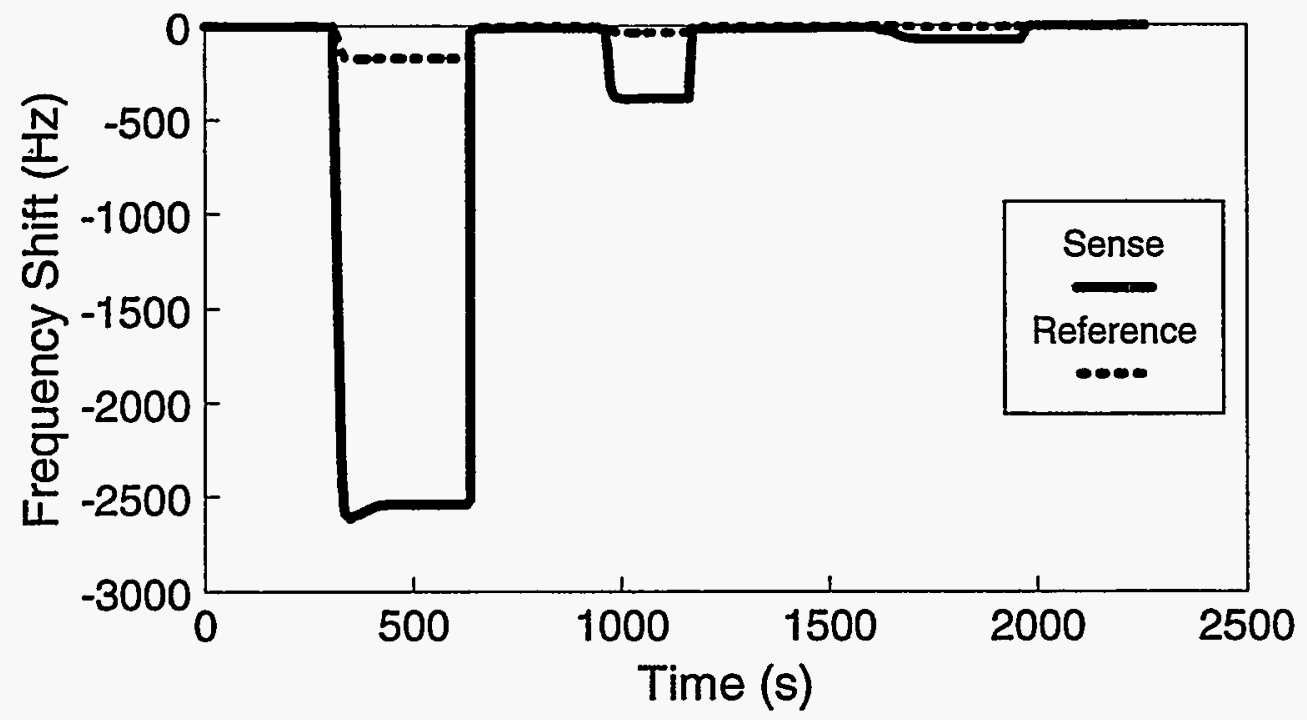

Figure 4. Use of a poly-(isobutylene)-coated sense resonator and an uncoated reference resonator to sense three different concentrations of trichloroethylene $(4.4 \%, 0.9 \%$, and $0.2 \%)$.

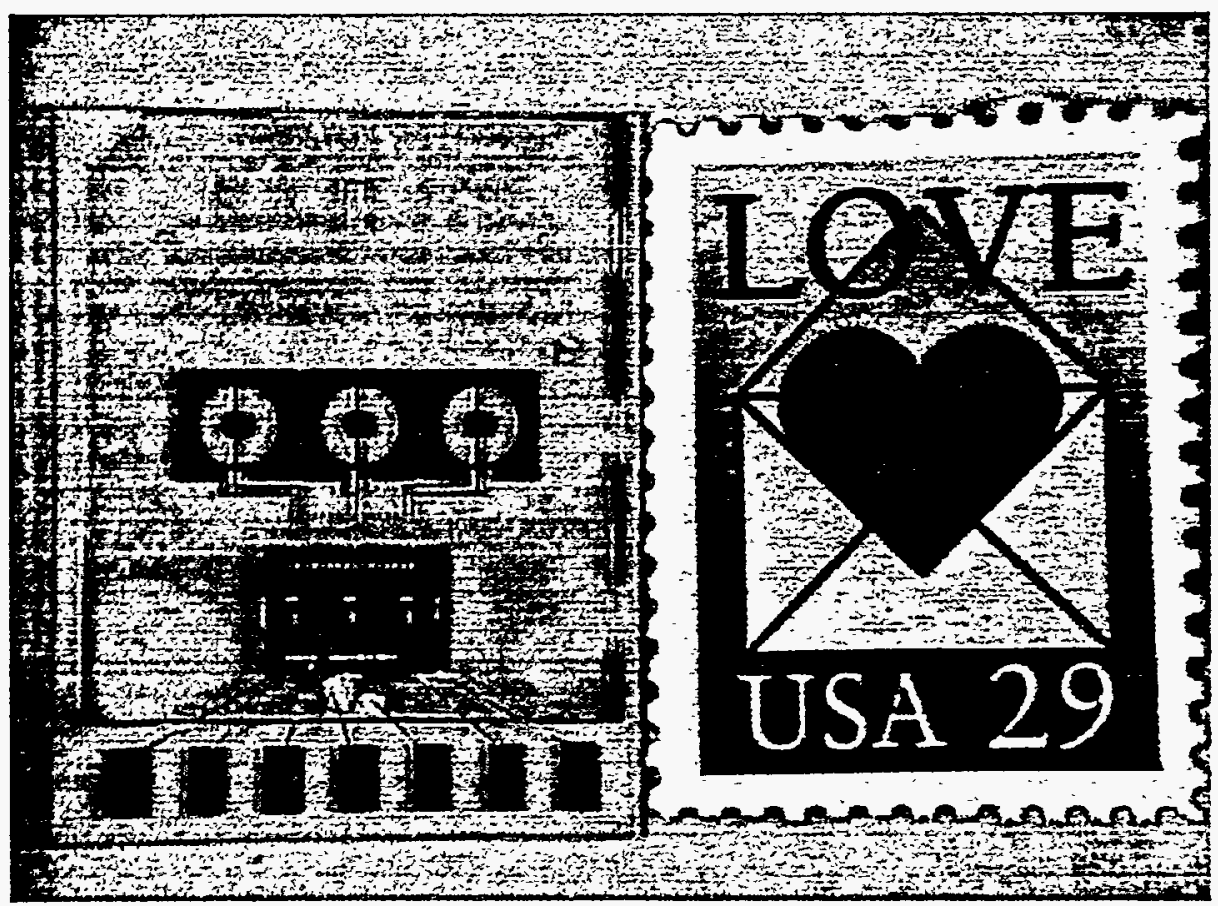

Figure 5. Chemical sensor platform containing three $22 \mathrm{MHz}$ bulk acoustic wave resonators with attached CMOS driver IC. 